\title{
LOS PLANTEAMIENTOS SOCIALES Y ECONÓMICOS DEL LIBERALISMO EXALTADO EN EL TRIENIO CONSTITUCIONAL CUBANO
}

\author{
MANUEL HERNÁNDEZ GONZÁLEZ \\ UNIVERSIDAD DE LA LAGUNA
}

\begin{abstract}
RESUMEN: Este trabajo aborda el estudio de los planeamientos sociales y económicos del liberalismo exaltado en la Cuba del Trienio Constitucional. Analiza su procedencia social, entre profesiones liberales, comerciantes y militares y sus fuentes de financiación en la burguesía peninsular. A continuación se aproxima a su política económica, fundamentada en una política arancelaria favorable al autoconsumo interno y la importación peninsular y en el reparto de tierras entre campesinos pobres blancos. La preocupación por los mulatos y negros libres fue, sin embargo, marginal.
\end{abstract}

PALABRAS CLAVES: Liberalismo exaltado, sacarocracia, burguesía comercial, Constitución de Cádiz, sociedades secretas, política arancelaria, desamortización y reparto de tierras.

\section{THE SOCIAL AND ECONOMIC APPROACHES OF LIBERALISM EXALTED IN THE CUBAN CONSTITUTIONAL TRIENNIUM}

\begin{abstract}
This work deals with the study of the social and economic planning of exalted liberalism in the Cuba of the Constitutional Triennium. It analyzes its social origin, between liberal professions, merchants and the military and its sources of financing in the peninsular bourgeoisie. He then approaches his economic policy, based on a tariff policy favorable to internal self-consumption and peninsular imports and in the distribution of land among white poor peasants. The concern for mulattos and free blacks was, however, marginal.
\end{abstract}

KEYWORDS: Exalted Liberalism, sacarocracy, commercial bourgeoisie, Constitution of Cádiz, secret societies, tariff policy, disentailment and land distribution. 


\section{Un grupo formado por militares $y$ profesiones laborales $y$ financiado por comerciantes peninsulares.}

La restauración del régimen liberal en 1820 no fue bien recibida por las clases dirigentes cubanas. El lustro 1815-1819 había sido uno de los más boyantes de la historia del azúcar cubano. La paz en Europa y Norteamérica había estimulado la demanda. La importación de esclavos se había incrementado considerablemente, alentada por la amenaza de la supresión de su tráfico por las reiteradas presiones del Gobierno británico. Fue una etapa de intensa colaboración entre la burocracia española y la oligarquía insular. La legislación española refrendaba esa política favorable a los intereses de la sacarocracia. En 1817 se suprime el estanco del tabaco, el 23 de julio de 1818 se concede el derecho de comercio libre. El decreto de 16 de julio de 1819 daba validez a todas las concesiones de bienes municipales, lo que proporcionaba a los plantadores de azúcar entera disponibilidad sobre estas tierras en detrimento de los pequeños cultivadores. Esa situación en extremo favorable parecía quebrarse con la restauración de la Constitución gaditana. Su carácter representativo relativamente abierto y centralista, y, sobre todo, la existencia de una prensa libre, eran una fuente de inestabilidad que podría ser origen de perturbaciones sociales peligrosas en una sociedad esclavista.

El desconcierto de las clases dirigentes cubanas fue aprovechado por el partido liberal exaltado ${ }^{1}$. La guarnición peninsular habanera será el núcleo principal de esa organización, denominada piñerista por su promotor, el sacerdote cántabro Tomás Gutiérrez de Piñeres, radical en su defensa del constitucionalismo y opuesto al poder político de la oligarquía criolla. Uno de sus principales ideólogos, Diego Correa, lo definió como integrado por “ciudadanos honrados, artesanos industriosos, ricos propietarios y comerciantes acaudalados sin tacha legal en sus opiniones ni vida privada, son el plantel de la milicia nacional local de la ciudad de La Habana, el antemural de las libertades patrias y del honor nacional”. Los denominó "acreditados patriotas" como Sangroniz, Madrazo, Zavala, Acosta, Arroyo, Amat, Betérbide, Martínez, Gordillo, Hernández, Campe, Hevia, y los hermanos García Fernández y otros buenos españoles europeos, canarios y naturales del país que profesaban las máximas constitucionales y liberales. Se erigían como portavoces de un sector socio-político que arriesgaba sus caudales, reputación y existencia para evitar que la fiel y patriótica isla de Cuba

\footnotetext{
${ }^{1}$ Una reflexión en profundidad sobre la ideología del liberalismo exaltado en España durante el Trienio en RUIZ JIMÉNEZ, Marta. "Una aproximación al discurso liberal exaltado durante el trienio liberal". Spagna contemporánea $\mathrm{n}^{\circ} 26,2004$, pp. 25-42.
} 
fuese "presa de una facción servil, independiente, que atenta directa e indirectamente desde la memorable época de 1808 contra la integridad del país" "2. En realidad estaba conformado por abogados, comerciantes y militares criollos y peninsulares unidos por su rechazo al poder omnímodo de la sacarocracia cubana.

Entre sus ideólogos destacaban los sacerdotes Tomás Gutiérrez de Piñeres y Pedro Gordillo, y los periodistas Diego Correa, y Tiburcio Campe, que se habían distinguido por su liberalismo radical en el primer período gaditano. Piñeres lo había defendido con energía en la primera etapa constitucional. Campe había sido su vocero en Cádiz. Correa en su etapa de Filadelfia se había opuesto abiertamente a las ideas independentistas. En Cádiz colaboró en su prensa y desafió el golpe absolutista fernandino en 1814, por lo que fue encarcelado en Ceuta. Liberado por la presión inglesa, apoyó la insurrección americana como antesala del liberalismo desde las páginas londinenses del Español Constitucional. Retornado a Madrid, fue uno de los redactores del órgano de los exaltados madrileños, El Conservador. El canónigo de la Catedral habanera Pedro Gordillo había sido diputado por Canarias en las Cortes y se había caracterizado por su liberalismo y su enaltecida defensa de las reformas más radicales como la abolición de los señoríos. El obispo Espada había tratado de expulsarlo de la Isla en 1819 por tales ideas. En ellos se puede plasmar las contradicciones del liberalismo exaltado, impulsor de un programa ideológico burgués radical, pero que apunta a un centralismo visceral en su concepción del mundo americano, antecedente indudable de la política del reinado de Isabel $\mathrm{II}^{3}$. Enarbolaban la bandera del estado centralista, afín a los intereses de la burguesía comercial española, que había inspirado la Constitución de 1812. Su énfasis se expresa en dos direcciones. La primera considerar a los criollos y en especial sus sectores hegemónicos como perpetuos conspiradores para reinstaurar el absolutismo y la independencia como principios asociados. La segunda apostaba por la radicalización de los gobiernos peninsulares para despojar del ejercicio del poder a las clases dominantes cubanas a través de su colaboración con las autoridades gubernamentales de la Gran Antilla y con los ejecutivos moderados y en su ejercicio del poder en la diputación provincial y en los ayuntamientos. Estos argumentos partían de su creencia en la incapacidad de vertebrar un proyecto liberal en la realidad social y étnica de la América española ${ }^{4}$ Para ellos sólo cabe en

\footnotetext{
${ }^{2}$ CORREA, Diego. A los constitucionales libres de ambos mundos, Madrid, 1823. p. 2.

3 Para una visión general de Cuba en ese período, véase PORTUONDO ZÚÑIGA, Olga. Cuba. Constitución y liberalismo, Santiago de Cuba: Ed. Oriente, 2008. 2 tomos. PIQUERAS ARENAS, José Antonio. Félix Varela y la prosperidad de la patria criolla. Madrid: Mapfre-Doce Calles, 2007.

4 Una valoración reciente del Trienio es el texto de MOLINER PRADA, Antonio. "En torno al Trienio Constitucional (1820-1823)". Rúbrica Contemporánea. Vol 1, nº1, pp.29-45. Sobre la política gubernamental y el papel desarrollado en ella por los liberales exaltados, véase BUSTOS, Sophie. La nación no es para nadie. El
} 
las colonias o su conversión en Haití o en un gobierno oligárquico reaccionario. Expusieron como argumento la inestabilidad de la Gran Colombia, el absolutismo del Imperio mejicano y la invasión haitiana en Santo Domingo tras la proclamación de la Independencia por Núñez de Cáceres.

Sin embargo, ponían poco énfasis ponían en aspectos sociales de la isla, como la esclavitud. Solo desentonaban las opiniones de Gordillo en su informe de 1819 en la Económica habanera, crítico con la economía de plantación. Desde esa perspectiva sus planteamientos son la única excepción en una concepción ideológica que en la práctica social coincidía con los criollos en la defensa del estatus quo. No cabe duda que existía una identidad de intereses entre la burguesía comercial española no vinculada directamente a la trata y los liberales exaltados. Se puede apreciar en Gutiérrez de Piñeres y en Diego Correa. El clérigo cántabro era el portavoz de los comerciantes de la muralla. Originario de Potes, se había establecido en La Habana a comienzos de 1790. Graduado de Doctor en Sagrada Teología, ejerció de profesor, de párroco de Jaruco de fiscal de la curia eclesiástica del obispado de La Habana. Era hermano de Juan Francisco Gutiérrez de Piñeres, uno de los miembros del Consejo de Indias opuesto al proyecto de Arango de 1792-1794, estrechamente conectado con los intereses gaditanos desde que, entre 1776-1780, había desempeñado la presidencia de la Casa de Contrastación. En 1807, tras el traslado a Cádiz de los consejeros ante el avance francés, fungió como presidente de la junta de gobierno de $1808^{5}$.El segundo estaba estrechamente vinculado con el comerciante de La Habana Juan Madrazo ${ }^{6}$.

\subsection{La pugna entre el pequeño comercio peninsular y la oligarquía criolla}

La estrecha relación de los liberales exaltados y el pequeño comercio peninsular se puede apreciar en el apoyo recibido por pequeños empresarios como los bodegueros. Su órgano de expresión, El amigo de la Constitución, expresaba que en la concepción de uno de los más caracterizados ideólogos del liberalismo criollo, el masón Abraham Elcid, no eran “ciudadanos los beneméritos catalanes y demás europeos, nuestros hermanos, que tienen

\footnotetext{
liberalismo exaltado en el Madrid del Trienio Liberal (1820-1823). Cortes, gobierno y opinión pública. Tesis doctoral. Universidad Autónoma de Madrid, 2017.

5 AMORES CARREDANO, Juan Bosco. "Liberalismo ilustrado y liberalismo político en Cuba: en torno a Francisco de Arango y Parreño (1764-1837)”. En CHUST, Manuel, FRASQUET, Ivana. Los colores de las independencias americanas. Liberalismo, etnia y raza, Madrid: C.S.I.C., 2009, pp.72-73. Fue también el célebre visitador que provocó la rebelión de los comuneros de Nueva Granada.

${ }^{6}$ Véase al respecto, HERNÁNDEZ GONZÁLEZ, Manuel. Liberalismo y masonería entre Europa y América. Diego Correa. Tenerife: Ediciones Idea, 2014.
} 
bodegas". En una junta celebrada para las elecciones en San Juan de Dios "profirió contra estos honrados ciudadanos multitud de expresiones bastante denigrativas", Precisaba que todo individuo con ejercicio conocido era un verdadero hombre de bien, que debía ser apreciado como tal ${ }^{7}$. En otro número de ese rotativo un articulista se quejaba de que en el convento de las Mercedes había presenciado el desaire contra

"un honrado ciudadano europeo, a quien se le vituperó atrozmente con las expresiones de bodeguero indecente y otras groserías vertidas por individuos que trabajan para el conde de O’Reilly, quienes se arrojan con el más criminal descaro a insultar frecuentemente a los hombres que son se someten a sufragar por los de su club".

Frente a esa caracterización ofensiva replicó que "un bodeguero es un ciudadano benemérito; y no lo son los perdidos, vagos, ni los tramposos a los caudales públicos"». Más adelante, registraron el incidente en las elecciones de la parroquia de Guadalupe. Estando sentados "en las bancas de honrados catalanes para por su turno sufragar sus votos", cansados de esperar, se levantaron y dejaron sus sombreros sobre esos asientos, como era costumbre. En ese instante Gabriel Peláez se acercó a ellos y se los quitó. Exclamó que tales sufragios no se habían "hecho para godos, que vayan a limpiarse los cicotes a sus tabernas o bodegas"”.

Debemos de tener en cuenta de que los liberales exaltados acusaban a la sacarocracia de valerse de holgazanes y mal entretenidos foráneos para presionar a los electores que se suponía contrarios a sus puntos de vista y evitar que procedieran a emitir sus sufragios. El amigo de la constitución describió con todo lujo de detalles algunas muestras de tales procedimientos, como los de un caraqueño de veinte años de edad, que, además de ser vago, reunía la tacha de haber robado en el coliseo. Afirmó que "este mamalón vive y muere en los cafés y no se sabe dónde pernocta porque no tiene casa ni hogar". Otro denunciado era "el famoso Pepe Churriplín, conocido también por José María Valdés”, que en las ferias por dos pesos se ejercitaba todas las noches "de bastonero en las cunas de gentes de color", su residencia en los zaguanes de los cafés, por lo que "fue pillado para la leva, con el objeto de que ocupase plaza en los buques o en Omoa; pero yo no sé porque lo soltaron"10. Pero no solo inculparon a esos agentes sino al mismo conde de O’Reilly. En El amigo de la constitución aseguraron que se encontraba apostado en el convento de la Mercedes "para detener aquellos

\footnotetext{
${ }^{7}$ El amigo de la Constitución $\mathrm{n}^{\circ} 30$ de 30 de septiembre de 1821.

${ }^{8}$ El amigo de la Constitución n $\mathrm{n}^{\circ} 40$ de 10 de oct de 1821.

${ }^{9}$ El amigo de la Constitución $\mathrm{n}^{\circ} 45$ de 15 de octubre de 1821.

${ }^{10}$ El amigo de la Constitución no suplemento al 43 de 13 de octubre de 1821.
} 
individuos inocentes que van a votar". Les exigía presentar las listas. Si no eran arregladas a su antojo, las hacía pedazos y les proporcionaba otras que llevaba en su faldriquera. Entendían que si tales procedimientos constituían por sí mismo "una conducta diametralmente opuesta a nuestro sistema reinante" ${ }^{11}$.

La instauración del régimen liberal en la Gran Antilla había sido impulsada por las guarniciones peninsulares asentadas en la Isla. Las clases dirigentes cubanas querían mantener a los funcionarios del antiguo régimen, tales como el intendente Alejandro Ramírez, el capitán general Juan Manuel Cagigal o al asesor del consulado Manuel Coimbra. Por ello eran incriminadas de continuistas y de albergar exigua lealtad a la Constitución gaditana. Los liberales exaltados denunciaron a estos gobernantes a través de sus órganos. Con imputaciones de corrupción y nepotismo, campaña en la que destacó el abogado habanero José María Aguiar desde las páginas del Tío Bartolo.

No es casual que uno de los portavoces del liberalismo exaltado, el habanero Botiquín constitucional, delatase en 1820 la separación de "los dignos oficiales del batallón de Tarragona" y felicitase "la buena opinión constitucional de los batallones de Málaga y Cataluña". Su apartamiento había acontecido "por no querer los primeros estar bajo las órdenes de unos jefes anticonstitucionales". Los segundos el 16 de abril se habían opuesto a la acusación de tumultuarios vertida por "viles impostores y caudillos del servilismo". Manifestaban asimismo que la diputación provincial no había tomado las providencias necesarias para que Alejandro Ramírez mostrase al público los estados mensuales de los caudales de las cajas nacionales, "a pesar de los reclamos hechos por medio de la imprenta, particularmente El Bartolo". Aseveraba que tal laxitud podía deberse a su calidad de vocal nato de ese organismo o por imponer "el nombramiento que obtuvo de Intendente" ${ }^{12}$.

\subsection{La animadversión exaltada al clero criollo y a la sacarocracia}

La redacción del Esquife, el principal rotativo del liberalismo exaltado en el Trienio, que modificó en varias ocasiones su subtítulo en función de la política represiva emprendida contra la libertad de imprenta por los jueces de censura, fue especialmente contraria a la posición "criollista" del clero cubano, personificada en el obispo Espada y muy especialmente en el santiaguero Juan Bernardo de O’Gavan y Guerra, deán y provisor de la Catedral habanera y diputado electo en 1820, sin duda uno de los más conspicuos representantes del

${ }^{11}$ El amigo de la Constitución $\mathrm{n}^{\mathrm{o}} 30$ de 30 de septiembre de 1821.

12 El botiquín constitucional n'39 .La Habana, 1820. 
sector criollo y firme partidario de la continuidad de la trata. Se indignó al ver "el perversísimo destino que algunos canónigos daban a los diezmos y primicias de la iglesia de Dios, empleándolos contra el mismo Dios y la misma iglesia, contra la tranquilidad y la libertad de los honrados labradores que los pagan". Estimó de poco generosa la conducta del cabildo catedralicio habanero al requerir el reintegro de la cuarta parte de los diezmos, de que se le había privado para el socorro de la Península ${ }^{13}$.

La ofensiva del liberalismo exaltado se tradujo también en una censura frontal de la clase dirigente cubana, como se puede aprecia en la "amistosa advertencia" de Evaristo Sánchez:

"Si don Joaquín... no desiste de incomodarnos con sus ridículas pretensiones y de insultarnos con sus cartas llenas de injurias que no estamos dispuestos a sufrir, tenga por cierto, no lo dude, que lo zampamos en el Cayo a ser interprete de los cangrejos con algunas otras adiciones que le harán sentir su imprudencia" ${ }^{14}$

o en su amenaza a Luis Peñalver de desistir de hablar

"en sus corrinchos de la manera escandalosa que acostumbra contra los editores de los papeles públicos, tenga por cierto, no lo dude, que cada uno en particular y todos ellos en general, le harán sentir tamaña impudencia, haciendo notorias sus grandísimas e incurables mataduras".

Fueron recriminadas "sus hazañas, desde antes que nadie; el que menos de nosotros tiene recopilado material bastante para hacerle sacar los colores a la cara”. Se apuntilló que ya no se hallaban "en la desgraciada época en que se le doblaba la rodilla, y él hacía lo que quería y le daba la gana, imponiendo leyes que unos obedecían por temor a su afilada espada y otros por su acreditada petulancia" ${ }^{\prime 15}$.

Ante la reorganización del partido criollista, cuyo líder fue el conde de O’Reilly, las diatribas contra esa organización fueron frontales por parte de los liberales exaltados, como se puede apreciar en este texto: "El que se deje seducir del partido orellano, sepa que está excomulgado, porque es el club de los serviles, enemigos de Dios, del trono y de nuestro actual gobierno". Los caracterizaba por sus muchos crímenes, que describían de "traidores, otros por ladrones e inteligentes en abrir agujeros de abajo para arriba en las azoteas otros por entregadores de castillos y otros en fin por afrancesados, tramposos y petardistas. Muchos entre estos son distinguidos los unos porque tienen taladradas las orejas, los otros por las caracas de paleta y el color cetrino como verdaderos excomulgado"16.

${ }^{13}$ El esquife arranchador $\mathrm{n}^{\circ} 12$. La Habana, 18 de septiembre de 1820

${ }^{14}$ El esquife arranchador $\mathrm{n}^{\circ} 10$. La Habana, 6 de septiembre de 1820.

15 El esquife arranchador $\mathrm{n}^{\circ} 21$ La Habana ,14 de octubre de 1820.

${ }^{16}$ El esquife constitucional alias arranchador de serviles e impertérrito declamador $\mathrm{n}^{\circ} 134$. La Habana, 13 de diciembre de 1821. 
Ellos se definían a sí mismos como "amantes del bien público y entusiastas de la libertad por principios, por convicción, por índole y temperamento, quisiéramos que todos los individuos de esta nación, regenerada tan felizmente hace año y medio, se conociesen solamente por el distintivo más honroso para el hombre, a saber con el título de ciudadano". Aunque se les acusaba de "sinónimo de revoltosos, de sedicioso, de anarquista, de republicano y otros" y se había afirmado con mucho énfasis Era un exaltado para indicar que era un hombre execrable y peligroso, sin embargo "no se duermen en las pajas, ven los peligros donde están, mas no se abaten ni se arredran, el amor a la libertad los hace suspicaces, la experiencia de los hombres les impone la ley de ser muy cautos". Ante las necesidades de la patria "reclaman medidas vigorosas y enérgicas del gobierno" ${ }^{17}$.

\section{La batalla por el control de la prensa y la masonería}

Los exaltados trataron de hacerse con el poder en la isla. Sin embargo su influencia era muy reducida. Fuera de La Habana, su implantación era escasa. Sólo podían imponer su hegemonía mediante el control del ayuntamiento habanero y a través del beneplácito y alianza con las autoridades designadas por el Gobierno. Los sectores altos e intermedios criollos coincidieron que era vital para ellos su unificación en un proyecto común que garantizase la estabilidad y arrebatase esa corporación municipal a los piñeristas. Fue clave el control de la Diputación Provincial por las clases dirigentes insulares, dada su total hegemonía en el resto de la Isla. El conflicto entre ambas instituciones será una constante durante el Trienio. Los criollos vieron en la conquista del cabildo capitalino la batalla final para desvanecer el control exaltado. De ahí la aguda conflictividad de sus procesos electorales anuales.

La alianza entre la Diputación provincial el Capitán General se convirtió en un arma letal contra los medios de comunicación controlados por el liberalismo exaltado. Cuando este todavía hegemonizaba el ayuntamiento capitalino, Gutiérrez de Piñeres, en un folleto fechado el 27 de diciembre de 1820 expuso que la consulta de ese organismo a la máxima autoridad de la Isla pretendía inferir una herida mortal a la libertad de imprenta. Al abrogarse el Jefe Superior Político la autoridad legislativa, destruía el reglamento de imprenta. Con ello nadie se atrevería a escribir contra los abusos de los funcionarios públicos por el temor de verse encarcelados si "la Junta Provincial de Censura calificara los impresos de subversivos o seductivos de desobedecer a las autoridades"18.

${ }^{17}$ El amante de si mismo n³3. La Habana, 25 de mayo de 1822.

${ }^{18}$ GUTIÉRREZ DE PIÑERES, Tomás. Los abusos se radican si se toleran los errores, La Habana, 1820. 
La hegemonía alcanzada por el liberalismo criollo en 1822 tuvo uno de sus ejes cardinales en el control de la opinión pública, cimentado sobre dos pilares esenciales: la prensa y la masonería. Su victoria en esos dos frentes hizo perder una considerable influencia al piñerismo. Los regimientos de Málaga y Cataluña traían "su logia ambulante que dependía del Oriente de Madrid y trabajaba aisladamente iniciando un número considerable de personas". La batalla por el control de las del rito escocés había comenzado entre los partidarios de su dependencia del Gran Oriente español y los de su ruptura con él. Los españoles, agrupados en el liberalismo exaltado, combatieron dentro de él a los criollistas. Como refleja un anónimo cronista, "la misma división que existía fuera se introdujo en los talleres y los piñerinos y masones empezaron a convertirse en criollos y godos, llegando a establecerse templos donde el lugar de nacimiento era documento único con que se admitían y rechazaban"19. Agentes del Gran Oriente llegados desde Granada, "que pretendía serlo del de aquî", abrieron planchas, junto con otros dos madrileños. Por uno de ellos se había nombrado Grande Inspector grado 33 a José Antonio Roca Sancti Petri, coronel y segundo comandante del regimiento de Málaga, que se había hecho célebre por su intento de hacer deponer al capitán general Cagigal ${ }^{20}$.

Desde los primeros momentos los piñeristas trataron de contrarrestar la penetración en las logias de los miembros de la elite oligárquica. De ahí que Los Filantrópicos del Cayo denunciasen la erección de "una cofradía que se llama del Anillo verde", similar a la establecida en España por los llamados afrancesados ${ }^{21}$, que evaluaban

“contraria a los derechos del pueblo, al código sacrosanto de nuestra regeneración política y a los verdaderos filantrópicos hijos de la luz, que son los que con sus trabajos nos han proporcionado la dulce dicha que hoy gozamos, sacándonos de las tinieblas en que yacíamos confundidos, y poniéndonos en triunfo en medio de la libertad que hoy respiramos".

Con esa imputación querían impedir su introducción, por entender que amaban "cordialmente a esos hijos predilectos de la lu₹, a quienes ahora y siempre hasta que nos dure el aliento los amaremos como a verdaderos hermanos, no dudando sacrificarnos en su obsequio",22.

\footnotetext{
${ }^{19}$ ANÓNIMO: "La Habana. Año 1825. Ojeada sobre el Estado de la isla de Cuba durante los cuatro años de la Constitución”. Nota previa de Alberto Gil Novales. Trienio n50. Madrid, 2007, pp. 152 y 159.

20 "La Habana en 1825", pp. 161-162.

${ }^{21}$ Véase sobre la sociedad del anillo el clásico texto de DÉROZIER, Albert, L'bistoire de la Sociedad del Anillo de Oro pendant le triennat constitutionnel 1820-1823, París, Les Belles Lettres, 1965. Más recientemente, el artículo de BUSTOS, Sophie. "El 7 de julio de 1822. La contrarrevolución en marcha”. Revista Historia Autónoma ,4 (2014), pp. 129-143.

${ }_{22}$ El esquife constitucional alias arranchador $\mathrm{n}^{\circ} 138$. La Habana, 6 de marzo de 1822.
} 
El objetivo de los liberales criollos fue liquidar su hegemonía a través de la fusión de escocistas y regulares, que se verificó el 7 de noviembre de 1822 con la erección de la Gran Logia Española del Rito de York. Los exaltados les acusaron de ruptura con el Gran Oriente español. Dedujeron que "se aspiraba a la independencia política de España, siendo el primer paso la independencia masónica que acababa de acordarse". Era cierto que una minoría apostaría por la ruptura, pero, como el cronista anónimo subraya, "fue una calumnia con que intentó cubrir sus miras interesadas el jefe que hemos mencionado (Roca). Ella exasperó a muchísimos buenos y despertó a los agentes de Méjico y Colombia para trabajar, como lo hicieron después" ${ }^{23}$. Basta analizar las autoridades masónicas que resultaron de este proceso para entender la efectividad de tales propuestas y la claridad meridiana de sus planteamientos, como lo ejemplifica la designación del conde de O'Reilly, como Gran Maestreo. Regidor, Alguacil Mayor perpetuo de La Habana, sería premiado, y no es ironía, tras la abolición del régimen liberal, con las Grandes Cruces de las órdenes San Hermenegildo y de Isabel la Católica el 28 de abril de $1824^{24}$.

La victoria de los segregacionistas explica que los liberales exaltados optasen finalmente por integrarse en la comunería, apenas recién constituida en la Península y que fue promovida en La Habana por un oficial de marina. En sus estatutos locales se prohibía en ella la entrada de cubanos. Se constituyó por "todos los europeos exaltados y, siendo esencialmente los el partido del Padre Piñeres, por identidad de principios, se unieron y formaron una masa que llamaron de liberales netos muy difíciles de contrarrestar" ${ }^{\prime 25}$. Como ha estudiado Marta Ruiz Jiménez, esta organización surgió en España como una escisión de la masonería despojada de todo su simbolismo, por lo que presenta elementos muy parecidos a la génesis de la cubana ${ }^{26}$.

La otra gran batalla fue la de la prensa ${ }^{27}$. Su censura se afianzará con el decreto de 13 de enero de 1821, que atribuía las funciones judiciales a jueces designados por la diputación provincial, bajo la supervisión del Jefe Superior Político. Con esa decisión los alcaldes le cedían su anterior jurisdicción. El ayuntamiento de La Habana recurrió en abril de 1821 a las

\footnotetext{
23 “La Habana en 1825”, p. 162.

${ }^{24}$ HERNÁNDEZ GONZÁLEZ, Manuel. Liberalismo, masonería y cuestión nacional en Cuba (1808-1823), Tenerife: Ediciones Idea, 2012.

25 "La Habana en 1825", p. 162.

${ }^{26}$ RUIZ JIMÉNEZ, Marta. El liberalismo exaltado. La confederación de comuneros españoles durante el Trienio liberal, Madrid: Editorial Fundamentos, 2017.

27 Véase sobre la prensa, JENSEN, Larry J.: Children of colonial despotism. Press, Politics and Culture in Cuba, 17901840, Tampa: University of South Florida Press, 1988. SÁNCHEZ BAENA, Juan José: El terror de los tiranos. La imprenta en la centuria que cambió Cuba (1763-1868). Castellón: Universidad Jaume I, 2011. Desde la perspectiva peninsular el clásico ensayo de ZAVALA, Iris. M. "La prensa exaltada en el Trienio constitucional: El Zurriago". Bulletin Hispanique Vol. 69 n³-4, pp.365-388.
} 
Cortes por considerar tal concesión vejatoria a la libertad de prensa. Sólo se recibió la callada por respuesta ${ }^{28}$. La política moderada prevalecía en las Cortes. En ella pesaba esencialmente la alianza con los liberes criollos. Los órganos exaltados realizaron una activa campaña contra ese dictamen, consciente de la seria limitación a sus cauces de expresión. Esta legislación derivó en resultados inmediatos. Piñeres fue condenado por un escrito a un año de internamiento en un convento. Las denuncias triunfaron en su mayor parte. Incluso se violentaron varios medios de comunicación, una campaña coincidente en sus inicios con el cese del Esquife arranchador el 19 de diciembre de 1821 y con el archivo de las tres últimas publicaciones en las que se delataba los excesos represivos de la fuerza policial a cargo de Domingo Armona y la complicidad de Mahy.

El 13 de abril de 1822 Armona, con una partida de hombres armados, entró el 13 de abril de 1822 en la imprenta de Pedro Nolasco Boloña, donde se editaba El Amigo de la Constitución y la destruyó completamente. Los exaltados arreciaron en su atribución a las autoridades locales. El primero en alzar su voz fue Segundo Correa con un manifiesto, "A los hombres libres", que calificó a Armona de "indigno de vivir en sociedad" y de "cobarde asesino”. Incriminado por éste ante los tribunales, se le encarceló en el Morro ${ }^{29}$. Se mofó en un nuevo folleto del tribunal de jurados. El Esquife Constitucional, periódico erigido a partir de la desaparición del Arranchador, reveló "la complicidad de estos asesinos protegidos por el gobierno (...) Si el Excmo. Sr. D. Nicolás Mahy no protegiera a hombres de semejante naturaleza no se atreverían ellos a cometer excesos jamás vistos ni oídos"30.

Tras la muerte de Mahy, su sucesor en la capitanía general y en la jefatura política, Sebastián Kindelan, continuó con la política obstruccionista de su predecesor, abiertamente favorable a los intereses de la elite criolla. El 15 de diciembre de 1822 remitió al secretario de Estado de Gracia y Justicia toda una serie de impresos de los liberales exaltados considerados como subversivos, cuyo objetivo en su opinión partía de "la maligna idea de exaltar los ánimos y fomentar la fatal discordia que amenazaba la ruina total de esta isla". Le expuso que no era ahora "cuando estos hombres han querido extraviar la opinión pública por medio de la imprenta". Desde la edición del Amigo de la Constitución, "fiscal del pueblo", había observado que en él no cabían sino "dicterios de la vida privada de los hombres virtuosos o que mejor llenan sus funciones". Entre ellos los de Juan Nogerido, "preso por sus escandalosas reincidencias en abusar de este bien", empleado "eternamente en firmar estos papeles

28 Archivo de las Corte españolas, Leg. 32, nº8.

${ }^{29}$ Archivo Nacional de Cuba, Asuntos Políticos. Leg. 20, nº 13.

${ }^{30}$ El esquife constitucional $\mathrm{n}^{\circ} 150$. 
incendiarios por el estímulo del dinero". Cuando él no lo efectuaba, lo verificaba "alguno de los ladrones a quienes sus delitos tienen en la cárcel, como es don Faustino Colla. Acudían incluso a un negro esclavo, "que está en presidio como acaba de suceder y se ha publicado por otras imprentas". Otro rotativo que juzgaba peligroso era ElEspañol libre, el único órgano que quedaba ya por esas fechas a los piñeristas, calificado como "alarmante e incitador". Concebía que se aprovechaba de la ley de imprenta, por lo que son "peligrosísimos sus redactores, haciéndose acreedores, como sucede, de que los hombres de bien los aborrezcan en todos sentidos y desprecian la lectura de tales producciones". Para frenarlo, asevero que había conseguido "por medios prudentes que las demás imprentas no publiquen discursos contraídos a los de aquellos". Alentaba su represión por entender que la obediencia a las autoridades constituidas era "la base más firme en que se funda la sociedad". Sostenía que "un pueblo donde todos quisiesen mandar y no fuesen obligados a obedecer, se destruiría con prontitud. Debilitado por las convulsiones interiores sería la fácil presa de un ambicioso extranjero" 31 .

Con esas perspectivas la única esperanza de los exaltados se centraba ya en una intervención directa del Gobierno. Sin embargo, el arrollador triunfo de los criollistas en las elecciones a diputados a Cortes pondría fin a sus anhelos de cambio a los albores de 1823. Uno de los más significados representantes del liberalismo criollo conservador, Tomás Gener, influiría decisivamente en la colocación como capitán general de Francisco Dionisio Vives, que relevaría el mandato provisional de Kíndelan el 2 de mayo de 1823 . $^{32}$ Se convertirá de esa forma en un personaje clave en una transición al absolutismo conforme a los intereses de la sacarocracia cubana, que se vislumbraba con el triunfo definitivo de la reacción con la invasión de los llamados Cien Mil Hijos de San Luis en ese mismo año.

\section{El proyecto económico del liberalismo exaltado sobre la ley de aranceles}

La escasez de propuestas en materia económica fue un rasgo característico de los liberales exaltados. Por ello es singular el texto que reproducimos a continuación, que resume en buena medida sus planteamientos en ese campo. Dado a la luz por uno de sus más caracterizados dirigentes, Genaro Güen, uno de los redactores del Esquife ${ }^{33}$, su artículo sobre

\footnotetext{
31 Archivo General de Indias, Santo Domingo, 1294.

32 Sobre esa coyuntura en la isla véase, HERNÁNDEZ GONZÁLEZ, Manuel. "Los vínculos entre el liberalismo criollo y los Soles y Rayos de Bolívar en el Trienio Liberal Cubano". Espacio, tiempo y forma. Historia contemporánea. No30 (2018), pp. 33-54.

33 De él solo sabemos que era bachiller, natural de La Habana, y vecino del barrio de la Salud, casado y de
} 
los aranceles, uno de los temas capitales de debate en la sociedad isleña, arranca con un exabrupto contundente contra la oligarquía cubana:

"En aquellos países donde los grandes propietarios quieren ser exclusivamente los hijos predilectos de la naturaleza, el resto de los humanos debe retirarse a vivir en las selvas o a resolverse con santa unión a defender su causa en el tribunal competente, que no solo le declara la justicia, sino que con energía se le dé efectivamente".

Frente a ese poder omnímodo defiende que la tierra era de todos, "para que los hombres busquen en ella los frutos, que, desde su origen fueron criados para su sustento y conservación". No servía para servir a la avaricia de quienes la dominan casi en exclusiva para destinarla a objetos innecesarios a la vida y deducir "tesoros que suscitan entre la sociedad una clase de deidades más perjudicial y gravosa que aquellos fuertes de las selvas que dieron margen al pacto social”. Tales principios eran contradictorios con un pueblo libre, que no debía encaminarse hacia el privilegio de "una parte de él con perjuicio de las otras", concepción que aboga "imperiosamente a la aristocracia, con objeto de que siempre seamos vasallos de unos miserables reyezuelos" ${ }^{34}$.

El editorialista subrayó que la multitud de jóvenes de la isla no podía dedicarse solo a las carreras de "clérigos o frailes, abogados, médicos, cirujanos, papelistas o peluqueros, muchos destinos a que los infelices padres han estado constantemente dedicando a sus hijos". La causa de esa persistencia estaba motivada no solo por ausencia de protección de las artes, sino por alejar sus talleres "de su seno a la clase que es difícil se roce con otra grosera por esencia y cuya educación es enteramente opuesta". Estaba reflejando que los oficios estaban copados por los mulatos y negros, lo que impedía el acceso a ellos de los blancos pobres por los prejuicios raciales existentes. El menoscabo de los por él denominados empleos útiles les conducía inevitablemente a entregarse "a los vicios, a la corrupción y la holgazanería". De ahí la existencia en La Habana de "tantos tahúres, tantos ladrones, tantos perdidos, de aquí tanto atraso en la población”. Un panorama que derivaba en un número reducido de matrimonios, en un gran desarreglo en las costumbres, "cuyas consecuencias son la infidelidad, la prostitución, la seducción, el homicidio, el robo, la ingratitud, la insolencia, de aquí la degradación de un país”35.

profesión practicante de leyes y administrador de sus bienes. Así se firma en 1821 en un folleto denominado Sobre José Arango, en el que declamaba contra sus puntos de vista en Independencia de la isla de Cuba. BACHILLER Y MORALES, Antonio. Apuntes para la bistoria de las letras y de la instrucción pública en la isla de Cuba. La Habana: Cultural S.A., 1937. Tomo III, p.334.

${ }^{34}$ El esquife constitucional... no100. La Habana, 28 de julio de 1821, p.397.

35 El esquife constitucional... nº100. La Habana, 28 de julio de 1821, p.397. 


\subsection{La pequeña propiedad como panacea frente al latifundio}

Güen denunció que ese estado de cosas se fundamentaba en los estorbos a la promoción de la agricultura y la industria, cuya raíz radicaba en el hecho de que "la sexagésima parte de los habitantes se han apoderado de la tierra y el resto no tiene donde trabajar. Hay propietarios de leguas, lo hay de tantas fanegas o caballerías que de utilidades". $\mathrm{Ni}$ ellos ni sus descendientes podrían ponerla en cultivo "ni en cien ni en doscientas generaciones". Estaban ocupadas por ingenios "donde falta tiempo para sembrar caña y elaborar la azúcar, en cafetales donde todo es pompa, sin más objetos que café y en haciendas de unos ganados que solo ofrecen desiertos y montes". A consecuencia de todo ello el abastecimiento por el público de los renglones de primera necesidad se producía desde el exterior, lo que abocaba a que el mercado de La Habana, siendo hasta ahora un pueblo redimido de los horrores de la guerra "en las mesas no se sirva sino puro dinero"36.

El columnista contrapuso la acumulación de tierras con las ansias de los honrados padres de familia de búsqueda de una simple caballería "para ejercitar sus hijos con el arado y mantenerlos, enseñándoles de camino los primeros principios de la verdadera agricultura, que es la que se dedica a sembrar para vivir y no perecer de hambre". Se quejó del hecho de que los que poseían una pequeña propiedad se veían obligados a perder sus cosechar o quemarlas por ser "el objeto de los amos de la tierra que se venda la azúcar, hacen que se admita a los compradores cuando traen maíz, arroz, etc., todo lo cual, cuando llega al mercado, ha corrido por las manos de doscientos monopolistas". Prejuicios que equiparó con la marginación sufrida por las artes "porque aquí se traen ropas, zapatos, comidas, etc., haciendo zapateros, sastres, hojalateros, alfareros, etc." ${ }^{37}$. El objetivo de los liberales exaltados era atraerse con esa denuncia a los pequeños cultivadores y artesanos blancos, al vincular la libre exportación del azúcar de la que hacía gala la oligarquía con su predilección con el impulso de la importación de alimentos y manufacturas foráneas. De esa forma trataban de atraerse a esos votantes con un programa de aranceles alternativo que no solo favoreciese a la burguesía comercial española.

El liberal exaltado apuntó que se debía proporcionar todos los medios para que todos trabajen y se ocupen honestamente y tuviesen familias para evitar que "no hayan más perversos que aquellos que por inclinación aman la perversidad". Una felicidad para todos que vinculaba a la ley de aranceles, que consideraba más necesaria en La Habana que ningún

${ }^{36}$ El esquife constitucional... n ${ }^{\circ} 100$. La Habana, 28 de julio de 1821, p.397.

${ }^{37}$ El esquife constitucional... nº100. La Habana, 28 de julio de 1821, p.397. 
otro lugar de la nación "porque solo así pueden los habaneros ser laboriosos, frugales y tan virtuosos como su noble propensión lo pide y el gobierno lo estorba". De lo contrario, de nada serviría la represión de la delincuencia por no ser "remedios radicales, que buscan el mal en su origen, sino superficiales, que solo miran a los accidentes". Evaluaba que toda la oposición a ella se originaba por la imposición de ciertos gravámenes a los extranjeros en la introducción de sus manufacturas y en la extracción de los frutos. Entendía que ese era un procedimiento legítimo del que se valían las potencias, tales como Inglaterra y Francia porque "no hay otro modo para proteger y alentar la industria de casa". Se fundamentaba en el hecho de que ningún español podía llevar a Burdeos un cargamento de azúcar sin riesgo de perderlo, mientras que si lo efectuaba un francés no había ningún riesgo. Por ello se preguntaba por la causa de que los extranjeros tuviesen que pagar allí crecidos derechos y los naturales no. Lo justificaba porque sin esa disposición los galos no se dedicarían al comercio. Planteó que para ello no era necesario el estudio de la economía política, ya que tales nociones eran comprendidas por todos. En consecuencia, los opuestos a una ley aduanera pretendían "que nosotros permanezcamos haciendo el papel de bobos en la sociedad de las gentes"38.

\subsection{La atracción de las capas bajas e intermedias blancas y el reparto de tierras}

Los esfuerzos de los liberales exaltados se centraban en intentar atraerse a sus filas a los sectores pobres e intermedios blancos de la sociedad cubana, que eran los que tenían derecho a voto en el sistema electoral gaditano. Trataban de incorporarlos a sus filas. Confrontaban sus intereses con los de la sacarocracia, a la que acusaban de ser la única clase interesada en la supresión de los aranceles. Por eso advertían a los habitantes de la isla que ellos no eran los contrarios, "sino una pequeña parte de hacendados avarientos y egoístas que, cifrando toda su utilidad en vender el azúcar, lo demás le importa un bledo”. Aseveraban que nacía de una estupidez originada por su avaricia y soberbia. Les acusan de inconsciencia por no saber que la venta de azúcar a un precio ínfimo en otro mercado les privaba de la adquisición de la suya. Güen puntualiza el elevado coste de los alimentos de primera necesidad en La Habana como consecuencia de esa preferencia. Al no amparar su producción se veían expuestos "a las desgracias y acontecimientos que prepara la multitud de holgazanes, viciosos y perdidos por falta de acomodo". Ellos prescindían de esa realidad. Sin embargo, las restantes capas de la población las experimentan diariamente, por lo que quieren vivir "con la franqueza y la seguridad que la cultura exige" 39 .

${ }^{38}$ El esquife constitucional... n¹00. La Habana, 28 de julio de 1821, p.397.

${ }^{39}$ El esquife constitucional... n ${ }^{\circ} 100$. La Habana, 28 de julio de 1821, p.397. 
Los planteamientos de los liberales exaltados se ceñían a neutralizar el libre comercio propugnado por los hacendados con la estimulación de la industria y la agricultura de autoconsumo locales que tales impuestos aduaneros incitarían. De esa forma no perecerían, como invocaban ellos, por no tener "ni platos en que comer". Frente a ese argumento Güen respondió que

"con mucha gloria comeremos como los héroes romanos en las fuentes ordinarias, que nos proporcionan nuestras alfarerías y estimulados de la necesidad, que es la mejor maestra de los hombres, adelantaremos nuestro discurso. Ni ropa habrá con qué vestirnos... Mejor, entonces hilaremos nuestro algodón y sabremos hacer telas que nos cubran. Los derechos de aduana no cubrirán los gastos... Mejor, entonces no se pagarán sueldos innecesarios a tanto botarate que gravita sobre la sociedad". Con tales estímulos afirmaba: ¿De qué otro modo pasan los pueblos de la infancia a la virilidad?" 40 .

Una sátira vertida de forma anónima en ese mismo rotativo indicaba que los promotores del libre comercio defendían la permisión total de los efectos extranjeros por enseñar la experiencia "que las prohibiciones más que lo benefician, por producir necesariamente el contrabando", ya que se exportarían con devolución del derecho que hubiesen pagado. Sin control ninguno, reducidos los empleados de la aduana al mínimo posible, ironizaban que la salida libre de los buques "a la hora que le acomode, de noche y de día sin necesidad de pase". Como evidencia del carácter privilegiado de la agricultura, en particular de la azucarera, se propugnaba la exención de todo derecho a

"las tablas para hacer envases de azúcar, los clavos para su uso, las duelas, arcos y bocoyes vacíos, los géneros para sacos, los utensilios de ingenio y de toda labor agrícola, las máquinas e invenciones útiles, la herramienta de artesanos, los caballos, yeguas toda especie de animales"41.

La crítica contumaz a la oligarquía habanera fue personificada por Güen en tres peninsulares que habían hecho una considerable fortuna en la isla con la trata de esclavos, el comercio y las plantaciones azucareras: Santiago Cuesta Manzanal "que vino aquí con una

${ }^{40}$ El esquife constitucional... n ${ }^{\circ} 100$. La Habana, 28 de julio de 1821, p.397.

${ }^{41}$ El esquife arranchador.... No 13 . La Habana, 16 de septiembre de 1820.

${ }^{42}$ De la Cuesta y Manzanal emigró con sus hermanos Pedro y Tirso desde el Val de San Lorenzo (León). Fue comendador de la orden de Isabel la Católica y desde 1824 conde de la Reunión de Cuba. Contrajo nupcias con María de la Concepción González Larrañaga. Uno de sus hijas, María de las Mercedes, fue marquesa de Valero de Uría por su enlace con el rico hacendado Joaquín Pérez de Urria. Traficante de esclavos, llegó a exportar en 1819 junto con Pedro 1664 esclavos. Director del Banco de San Fernando, dueño de siete ingenios, su enlace con la hija de otro gran negociante azucarero, Bonifacio González Larrañaga, le llevó a aumentar su patrimonio no solo con plantaciones de caña sino con cafetales, potreros, fincas urbanas. Naviera, ferrocarriles, que 
mano atrás y otra adelante, tenga dos mil esclavos, ingenios y cafetales", en cuyo obsequio se hizo un folleto dado a la luz por uno de los más conspicuos representantes del liberalismo criollo, José Quintana Warnes, Gabriel Lombillo ${ }^{43}$ y Joaquín Gómez Hano de la Vega ${ }^{44}$,

\begin{abstract}
"que desde el mostrador de una tienda de ropas donde estaban de mancebos, hayan subido a ser hacendados y tengan otro tanto número de vasallos, que por pocos más, descendientes de otros de los mismos principios, quieran para sí todo, y estemos los demás con los mismos brazos cruzados" $"$.
\end{abstract}

El ideólogo de la sacarocracia liberal José de Arango llegó a decir al respecto que El Esquife quería repartirse los bienes de estos acaudalados comerciantes y hacendados como primer aldabonazo de ese proceso expoliador de "la lista de los hombres opulentos, cuyas propiedades deben repartirse", con lo que se conducía al vecindario al sobresalto y "la autoridad avizorada”. Era más que evidente el rechazo al poder omnímodo de la oligarquía habanera. El hacendado precisó que su programa abocaba a "relajar todas las subordinaciones" con la deposición incluso del obispo Espada, contemplado como rehén de la sacarocracia. Llegó a defender que propiciaban el reparto de las propiedades de las personas más ricas "entre los pobrecitos holgazanes", lo que "minaba la armonía social, destrozando el honor de muchos ciudadanos buenos, y negando el carácter de propietario con voto en la opinión pública a muchas clases estimables" ${ }^{46}$. De ahí que Güen insistiese que era preferible que los mares se tragasen la isla que "cuatro soberbiotes procuran hacer patrimonio suyo, como primogénitos del padre de los hombres, que nos mira a todos sin esa desigualdad y preferencia tan odiosa" ${ }^{\prime 7}$. Era imprescindible, para contravenirlo, que la ley de aranceles se llevase a efecto.

permitieron que acumulase un capital de 3238723 pesos. Véase al respecto, MARTÍNEZ MARTÍNEZ, Martín. Santiago de la Cuesta Manz̧anal, conde de la Reunión, León: CEA, 2012; TORNERO TINAJERO, Pablo. "Azúcar, esclavitud y racismo: oligarquía criolla y colonialismo en Cuba", Caravelle nº85. Toulouse, 2005, p.33.

43 Originario de la villa de Pedroso (La Rioja), fue también cruz de Isabel la Católica y Conde de Casa Lombillo en 1829. Se dedicó con sus tíos Bruno y José Herce al tráfico de esclavos. Dueño del ingenio San Gabriel, en 1831 se le concedió licencia para erigir mayorazgo. Véase, Francisco Xavier SANTA CRUZ Y MALLEN: Familias cubanas. La Habana, Ed. Hércules, 1943. Tomo III, pp.138-139.

44 Nació en Hazas de Cesto en Cantabria el 20 de septiembre de 1776, negrero desde su juventud, sería más tarde un el principal de La Habana durante la regencia de María Cristina de Borbón) y una de las mayores fortunas de la isla. Formó parte del círculo palaciego del capitán general Tacón y director del Banco de San Fernando. Sin descendencia, fueron socios suyos y herederos sus sobrinos y paisanos José María Cagigal Gómez y Rafael Toca Gómez y Hano de la Vega, primer conde de San Ignacio. Véase al respecto, QUINTANILLA, Joaquín F. La saga de los Quintanilla. Santander: Cantabria 4 estaciones, 2007, pp. 39-41; GONÇALVES, Dominique. Le plantear et le Roi. L'aristocratie havanaise et la Couronne d'Espagne (1763-1836). Madrid: Casa de Velázquez, 2008, pp.438 y 441.

${ }^{45}$ El esquife constitucional... n ${ }^{\circ} 100$. La Habana, 28 de julio de 1821, p.397.

46 ARANGO Y NÚÑEZ DEL CASTILLO, José. Nadie se asuste por la segunda y última explicación mía sobre la independencia de la isla de Cuba, La Habana, 1821, pp. 30 y 6. Sobre José Arango véase, HERNÁNDEZ GONZÁLEZ, Manuel. Liberalismo criollo y sacarocracia en Cuba. José Arango y Núnez del Castillo (1765-1851), Tenerife: Ediciones Idea, 2014, p.170.

${ }^{47}$ El esquife constitucional... no 100 . La Habana, 28 de julio de 1821, p.397. 
Culminó su exposición con un proyecto de reparto de las tierras de la recién suprimida orden betlemítica y de los realengos existentes, que serían por esas fechas muy pocos, "porque hoy están formando los estados de los grandes propietarios". Su criterio era favorecer en ellos la distribución de caballerías entre los padres de familia pobres, prohibiendo para su cultivo el empleo de esclavos. En cada lote se debería tener en cuenta "los plantíos que cada fundo debe tener para que no escasee la madera de construcción". Su objetivo era favorecer el autoconsumo a través de brazos libres, sin limitar "nuestra agricultura a la azúcar y al café". De esa forma depararía en "menos viciosos, buenas costumbres, mejor seguridad, más comodidad, más industria, más patriotismo y aquella unión que jamás pudo existir de buena fe entre señores y vasallos ${ }^{48}$. En definitiva, era un programa que conciliaba los intereses de los comerciantes peninsulares con los de los cultivadores y los artesanos pobres blancos, que habían sido perjudicados por la política acaparadora de las elites criollas, que había derivado en su expulsión de la provincia de La Habana para favorecer la economía de plantación esclavista.

\section{La excepción a la regla: el intento de atracción de los blancos pobres y los morenos por el Robespierre}

Dentro del sector liberal exaltado un elemento singular era el habanero Gabriel García Bravo, director del periódico El Sábelo Todo o el Robespierre habanero, un rotativo editado en La Habana en 1821 y que supero la veintena de números publicados ${ }^{49}$. García Bravo era un militar de unos cuarenta años en el advenimiento del Trienio, que había ejercido como sargento y subteniente en la plana mayor de blancos agregada al batallón de morenos. Había desertado el 6 de diciembre de 1813 y arrestado entre el 25 de noviembre de 1815 y el 24 de noviembre de 1817, que fue destinado al regimiento de La Habana. Había procedido a ello al ser propuesto para teniente y postergado "por su mala conducta", marchando a la Península a reivindicar la reparación de su agravio. Al fallar a su favor en 1820 obtuvo del capitán general la licencia absoluta para separarse del servicio ${ }^{50}$.

En el número 4 de El Sábelo Todo García Bravo publicó un artículo en que el que trataba de atraer a los pardos y negros cubanos a la causa liberal exaltada, a pesar de que el texto constitucional impedía su derecho al voto. Sostuvo en él que:

48 El esquife constitucional... n ${ }^{\circ} 100$. La Habana, 28 de julio de 1821, p.397.

${ }^{49}$ LLAVERÍAS, Joaquín: Contribución a la historia de la prensa periódica, La Habana: Archivo Nacional de Cuba, 1957. Tomo I, pp.378-379.

${ }^{50}$ Archivo General Militar de Segovia, Expediente personal de Gabriel García Bravo. 
“españoles pardos y morenos, jóvenes y ancianos, discretos e ignorantes levantad con justa razón vuestras manos al cielo y bendecid una y mil veces la mano benefactora que escribió las leyes que cual otro Solón dictó el soberano congreso nacional al tiempo que señaló los fundamentos que hoy hacen honor a la grande nación a que tenéis la gloria de pertenecer".

Ese sagrado libro les ponía "a cubierto de toda tropelía, y os abre por medio de la virtud, que es el alma de toda la sociedad las puertas al merecimiento" y les convertía en "iguales ante la ley, que previene que vuestras propiedades sean defendidas por el escudo de ellas y que indistintamente se abroquela en defensa de todos vuestros derechos individuales". Asimismo les garantizaba "el sagrado derecho de la inmunidad de vuestros hogares, por muy miserables que sean" con "tanto respeto y consideraciones como el palacio suntuoso del más acaudalado". También, con la égida de la ley, quedaban exentos de ser condenados "a una ignominiosa prisión, como antes habéis experimentado", sin ser vejados ni mortificados. Con ello habían salido "de la esfera del vasallaje y la tiranía que tanto deprimió hasta aun los fueros naturales", por lo que con este código alcanzarían el estatus de "súbditos moderados y amantes a la ley". Además les posibilitaba:

"el derecho de publicar por medio de la imprenta libre vuestras ideas o ya expresando los desahogos de que es susceptible el hombre honrado cuando experimenta la injusticia, el despotismo y los efectos de la tiranía", por lo que debían defenderlo "aun a costa de vuestra vida" 51 .

Trataba de integrarlos en esa corriente ideológica, aun a sabiendas de que no se le habían reconocido sus derechos de participación en las contiendas electorales y en la soberanía popular.

Gabriel García denunció también a las condiciones de vida y el trato vejatorio que sufrían los soldados del batallón de moreno. Arreció también contra las condiciones de vida de las clases bajas:

"Los pobres de La Habana, si les somete algún achaque que exija ponerles puchero, carecen de tan preciso alimento, si no tienen doce reales cuando menos para una gallina y tres pesos para condimentarlo, sin más razón ni causa que la de no haber los señores capitulares mandado establecer una recova donde se vendan aquellas a todas las horas del día y de la noche".

Al aclarar el día, podrían llevarse las sobras los hospitales, obligando a sus administradores a su compra. Aseveraba que esa medida debía de adoptarse de inmediato porque "los pobres somos infinitamente más que los ricos”. Con ella se les proporcionarían conveniencias que le harían la vida más agradable por consumirla “trabajando para pagar los crecidos alquileres

${ }^{51}$ El Sábelo Todo o Robespierre habanero nº 4. La Habana, 14 de abril de 1821. 
de las casas que habitan", que atribuyó a la crueldad de la clase propietaria ${ }^{52}$. Fue sin duda un testimonio singular entre los partidarios del liberalismo exaltado, no obstante, no dejó de ser un caso excepcional en un grupo en el que sus preocupaciones e intereses basculaban indudablemente hacia las capas mercantiles y a lo sumo hacia los grupos intermedios blancos.

\section{Conclusiones}

El liberalismo exaltado trató de vertebrar una alternativa crítica al poder omnímodo de la sacarocracia cubana, que había obtenido grandes concesiones de la Monarquía en el período absolutista y que no recibió con buenos ojos la restauración en el Trienio de un régimen como el constitucional gaditano que proporcionaba el voto a los cabezas de familia blancos independientemente de sus niveles de renta. El ayuntamiento de La Habana fue la única corporación que este grupo político logró conquistar en los dos primeros años del régimen liberal. Formado mayoritariamente por militares de los batallones fijos asentados en la capital cubana, por profesiones liberales y comerciantes criollos y peninsulares, intentó atraerse con una nueva política económica a las capas de campesinos y artesanos blancos pobres que habían sido perjudicadas por la política gubernamental abiertamente favorable a la oligarquía habanera, que había generalizado la trata y originado la expulsión de las tierras que habían arrendado por generaciones en esa provincia para erigir en ellas grandes haciendas esclavistas de azúcar y café. Pero su proyecto, financiado por los comerciantes peninsulares favorables a la formulación de un sistema arancelario que gravase las importaciones y estimulase el autoconsumo interno y las transacciones con la Península, chocó con la oposición del capitán general y jefe superior político, que se convirtió en un estrecho aliado de las clases altas, y con el control hegemónico de los criollos de la diputación provincial. Aunque en sus planteamientos no se plasmaron con amplitud en un programa en materia económica, al predominar en sus rotativas y folletos, como casi único y reiterativa justificación la exaltación de las máximas constitucionales, no obstante escritores como Güen trataron de desarrollar su proyecto económico. Salvo el caso excepcional de Gabriel García y su El Sábelo Todo o Robespierre habanero, no figuraba en sus puntos de vista la atracción a sus filas de los mulatos y negros libres, a los que, por otra parte, se les negaba el derecho al voto en la Constitución de 1812.

Sin embargo, las elites sociales cubanas, al ejercitar en su provecho los mecanismos que se le proporcionaban desde estas instituciones, pudieron dinamitar, en colaboración con

${ }^{52}$ El Sábelo Todo o Robespierre habanero n ${ }^{\circ} 7$. La Habana, 26 de abril de 1821. 
sectores intermedios criollos, los medios de comunicación exaltados y dominar las asociaciones como la masonería que podrían influir en la opinión pública. La censura e incluso la aniquilación de la prensa liberal exaltada y su hegemonía en los talleres de los ritos de York y escocés se convirtieron en pasos decisivos en su desmantelamiento que finalmente alcanzaron con su triunfo en las elecciones municipales y en las de diputados a Cortes, con lo que se dio por desmantelada su organización a comienzos de 1823.

\section{Bibliografía}

AMORES CARREDANO, Juan Bosco. "Liberalismo ilustrado y liberalismo político en Cuba: en torno a Francisco de Arango y Parreño (1764-1837)”. En CHUST, Manuel, FRASQUET, Ivana. Los colores de las independencias americanas. Liberalismo, etnia y raza, Madrid: C.S.I.C., 2009.

ANÓNIMO: "La Habana. Año 1825. Ojeada sobre el Estado de la isla de Cuba durante los cuatro años de la Constitución”. Nota previa de Alberto Gil Novales. Trienio n50. Madrid, 2007.

ARANGO Y NÚÑEZ DEL CASTILLO, José. Nadie se asuste por la segunda y última explicación mía sobre la independencia de la isla de Cuba, La Habana, 1821.

BACHILLER Y MORALES, Antonio. Apuntes para la historia de las letras y de la instrucción pública en la isla de Cuba. La Habana: Cultural S.A., 1937. 4 tomos.

BUSTOS, Sophie. La nación no es para nadie. El liberalismo exaltado en el Madrid del Trienio Liberal (18201823). Cortes, gobierno y opinión pública. Tesis doctoral. Universidad Autónoma de Madrid, 2017.

BUSTOS, Sophie. "El 7 de julio de 1822. La contrarrevolución en marcha". Revista Historia Autónoma, 4 (2014), pp. 129-143.

CORREA, Diego. A los constitucionales libres de ambos mundos, Madrid, 1823.

DÉROZIER, Albert, L'bistoire de la Sociedad del Anillo de Oro pendant le triennat constitutionnel 1820-1823, París, Les Belles Lettres, 1965.

GONÇALVES, Dominique. Le plantear et le Roi. L'aristocratie havanaise et la Couronne d'Espagne (17631836). Madrid: Casa de Velázquez, 2008.

GUTIÉRREZ DE PIÑERES, Tomás. Los abusos se radican si se toleran los errores, La Habana, 1820.

HERNÁNDEZ GONZÁLEZ, Manuel. Liberalismo criollo y sacarocracia en Cuba. José Arango y Núnẽz del Castillo (1765-1851), Tenerife: Ediciones Idea, 2014.

HERNÁNDEZ GONZÁLEZ, Manuel. Liberalismo, masonería y cuestión nacional en Cuba (1808-1823), Tenerife: Ediciones Idea, 2012.

JENSEN, Larry J. : Children of colonial despotism. Press, Politics and Culture in Cuba, 1790-1840,. Tampa: 
University of South Florida Press, 1988.

HERNÁNDEZ GONZÁLEZ, Manuel. Liberalismo y masonería entre Europa y América. Diego Correa. Tenerife: Ediciones Idea, 2014.

HERNÁNDEZ GONZÁLEZ, Manuel. "Los vínculos entre el liberalismo criollo y los Soles y Rayos de Bolívar en el Trienio Liberal Cubano". Espacio, tiempo y forma. Historia contemporánea. No30 (2018), pp. 33-54.

LLAVERÍAS, Joaquín: Contribución a la bistoria de la prensa periódica, La Habana: Archivo Nacional de Cuba, 1957. 2 tomos.

MARTÍNEZ MARTÍNEZ, Martín. Santiago de la Cuesta Manzanal, conde de la Reunión, León: CEA, 2012.

MOLINER PRADA, Antoni. "En torno al Trienio Constitucional (1820-1823)". Rúbrica Contemporánea. Vol 1, nº1, pp.29-45.

PIQUERAS ARENAS, José Antonio. Félix Varela y la prosperidad de la patria criolla. Madrid: MapfreDoce Calles, 2007.

QUINTANILLA, Joaquín F. La saga de los Quintanilla. Santander: Cantabria 4 estaciones, 2007.SANTA CRUZ Y MALLEN, Francisco Xavier. Familias cubanas. La Habana: Ed. Hércules, 1943. 5 tomos.

PORTUONDO ZÚÑIGA, Olga. Cuba. Constitución y liberalismo, Santiago de Cuba: Ed. Oriente, 2008. 2 tomos.

TORNERO TINAJERO, Pablo. "Azúcar, esclavitud y racismo: oligarquía criolla y colonialismo en Cuba”, Caravelle n85. Toulouse, 2005.

RUIZ JIMÉNEZ, Marta. El liberalismo exaltado. La confederación de comuneros españoles durante el Trienio liberal, Madrid: Editorial Fundamentos, 2017.

RUIZ JIMÉNEZ, Marta. "Una aproximación al discurso liberal exaltado durante el trienio liberal”. Spagna contemporánea $\mathrm{n}^{\circ} 26,2004$, pp. 25-42.

SÁNCHEZ BAENA, Juan José: El terror de los tiranos. La imprenta en la centuria que cambió Cuba (17631868). Castellón: Universidad Jaume I, 2011.

ZAVALA, Iris M. "La prensa exaltada en el Trienio constitucional: El Zurriago". Bulletin Hispanique Vol. 69 n³-4, pp.365-388. 